Article

\title{
Photovoltaic Device Application of a Hydroquinone-Modified Conductive Polymer and Dual-Functional Molecular Si Surface Passivation Technology
}

\author{
Na Yeon Park ${ }^{1}$, Gwan Seung Jeong ${ }^{1}$, Young-Jin Yu ${ }^{1}$, Yoon-Chae Jung ${ }^{1}{ }^{\mathbb{D}}$, Jin Hee Lee ${ }^{2}$, Jung Hwa Seo ${ }^{2}$ \\ and Jea-Young Choi ${ }^{3, *(D)}$ \\ 1 Department of Metallurgical Engineering, Dong-A University, Busan 604-714, Korea; \\ nayeon2385@gmail.com (N.Y.P.); wjdrhkstmd12@gmail.com (G.S.J.); tq6284@naver.com (Y.-J.Y.); \\ dbsco0306@naver.com (Y.-C.J.) \\ 2 Department of Chemical Engineering, Dong-A University, Busan 604-714, Korea; dljh82@gmail.com (J.H.L.); \\ seojh@dau.ac.kr (J.H.S.) \\ 3 Department of Materials Sciences \& Engineering, Dong-A University, Busan 604-714, Korea \\ * Correspondence: cjy4395@dau.ac.kr
}

check for

updates

Citation: Park, N.Y.; Jeong, G.S.;

Yu, Y.-J.; Jung, Y.-C.; Lee, J.H.;

Seo, J.H.; Choi, J.-Y. Photovoltaic Device Application of a

Hydroquinone-Modified Conductive

Polymer and Dual-Functional

Molecular Si Surface Passivation

Technology. Polymers 2022, 14, 478.

https://doi.org/10.3390/polym14030478

Academic Editor: Tao-Hsing Chen

Received: 7 January 2022

Accepted: 18 January 2022

Published: 25 January 2022

Publisher's Note: MDPI stays neutral with regard to jurisdictional claims in published maps and institutional affiliations.

Copyright: (c) 2022 by the authors. Licensee MDPI, Basel, Switzerland. This article is an open access article distributed under the terms and conditions of the Creative Commons Attribution (CC BY) license (https:// creativecommons.org/licenses/by/ $4.0 /)$.

\begin{abstract}
In the last decades, the conductive polymer PEDOT:PSS has been introduced in Si-based hybrid solar cells, gaining noticeable research interest and being considered a promising candidate for next generation solar cells which can achieve both of low manufacturing cost and high power conversion efficiency. This study succeeded in improving the electrical conductivity of PEDOT:PSS to $937 \mathrm{~S} / \mathrm{cm}$ through a simple process of adding hydroquinone (HQ) to the pristine PEDOT:PSS solution. The results also showed that the addition of HQ to PEDOT:PSS(HQ-PEDOT:PSS) could not only dramatically improve the conductivity but also well-sustain the work function characteristics of PEDOT:PSS by promoting the formation of more continuous conductive-PEDOT channels without removing the insulating PSS. In this report, we reveal that the application of the HQ-PEDOT:PSS to the Si/PEDOT:PSS HSC could significantly improve the short-circuit current and open-circuit voltage characteristics to increase the power conversion efficiency of the HSCs compared to the conventional approaches. Moreover, we also treated the Si surface with the organic monomer, benzoquinone (BQ) to (1) passivate the excess Si surface defect states and (2) to improve the properties of the $\mathrm{Si} / \mathrm{PEDOT}$ :PSS interface. We show that BQ treatment is able to dramatically increase the minority carrier lifetime induced by effective chemical and field-effect passivation in addition to enhancing the wettability of the Si surface with the PEDOT:PSS solution. As a result, the power conversion efficiency was increased by $10.6 \%$ by introducing HQ and $\mathrm{BQ}$ into the fabrication process of the Si/PEDOT:PSS HSC.
\end{abstract}

Keywords: PEDOT:PSS; heterojunction solar cell; work-function; conductivity; passivation

\section{Introduction}

Photovoltaic (PV) cells have become increasingly important in their role as harvesters of sunlight as a major source of sustainable and renewable energy. Research devoted to the use of PVs to solve global environmental problems arising from growing energy shortages and greenhouse gas emissions has been actively ongoing for the past few decades. [1-3], Currently, monocrystalline and polycrystalline silicon (Si)-based PV technologies account for around $90 \%$ of the total solar cell market because of their non-toxicity, well established advanced microelectronics manufacturing technology, and long-term stability [4-7]. Conventional Si solar cells have a p-n junction structure which is known to provide highly effective charge separation and collection of photogenerated carriers in devices. Generally, the $\mathrm{p}-\mathrm{n}$ junction structure is formed by using a dopant diffusion process which requires high-temperature conditions $\left(\geq 800^{\circ} \mathrm{C}\right)$, which inevitably complicate the process and increase the manufacturing cost [8-10], From this standpoint, Si/organic heterojunction solar 
cells (HSCs) offer advantages compared with conventional cells in that Si/organic HSCs can be fabricated using low-temperature $\left(\leq 200^{\circ} \mathrm{C}\right)$ and low-cost processes (e.g., spin-coating) and offer a simple device structure. These advantages have resulted in HSCs being widely studied as the next-generation PV technology [11-13]. HSC devices are generally fabricated by using organic materials for the carrier selective layer to promote the extraction efficiency of photogenerated carriers in the devices. A wide range of organic materials, such as conductive polymers [14,15] small molecules [16,17] and fullerene derivatives [18,19] are currently being studied for this application.

Among all these materials, the $p$-type conductive polymer, poly(3,4-ethylenedioxythiop hene):poly(4-styrenesulfonate) (PEDOT:PSS), is one of the most widely studied materials for inclusion as the hole selective/transport layer or the transparent electrode material when fabricating HSCs owing to its relatively high thermal stability, electrical conductivity, and ability to transmit light [20-24]. However, coated PEDOT:PSS thin films (TFs) have low electrical conductivity of less than $1 \mathrm{~S} / \mathrm{cm}$, and this has been recognized as one of the major barriers in the way of further increasing the power conversion efficiency (PCE) of HSCs based on Si/PEDOT:PSS [25]. This problem arises because PEDOT:PSS exists in the form of a core-shell structure (Figure 1a) composed of a PEDOT-rich core and a PSS-rich shell, owing to the large difference in their molecular weights, as schematically illustrated in Figure 1a [26-28]. As a result, the discontinuous distribution of PEDOT as the conductive component prevents efficient charge carrier transport in the TF, as illustrated in Figure 1b [29-31]. Moreover, the excess amount of PSS in the PEDOT:PSS solution (e.g., PEDOT:PSS = 1:2.5 for PH1000) initially results in the formation of a PSS-rich top layer on the surface during TF formation (Figure 1b), causing a further increase in the electric resistance of the film, which acts as a barrier for external charge carrier extraction [31,32].

(a)

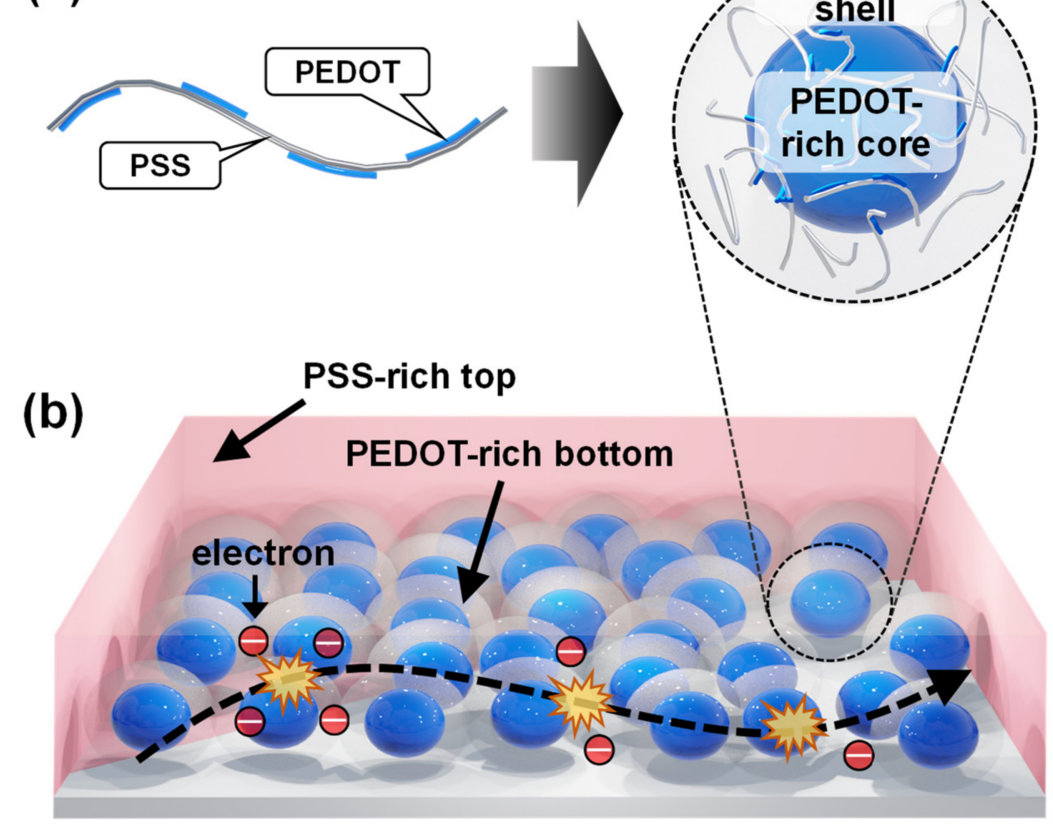

Figure 1. Schematic illustration of the (a) core-shell structure of PEDOT:PSS and (b) discontinuous distribution of conductive PEDOT in a coated pristine PEDOT:PSS TF.

Previous studies have reported an improvement in the electrical properties of PEDOT:PSS by using a secondary doping method to add polar solvents with a high boiling point, such as dimethyl sulfoxide (DMSO), glycerol, and ethylene glycol (EG). These solvents weaken the ionic interaction between PEDOT and PSS and then increase the size of the domains occupied by the conductive PEDOT in the PEDOT:PSS TFs [24,33]. Moreover, in addition to the above, the electrical conductivity can reportedly be improved by sub- 
jecting the coated PEDOT:PSS to post-surface treatment using DMSO, EG, or an inorganic acid as the solvent $[24,30,34]$. The purpose of this post-surface treatment is to remove the insulator-like PSS from the PSS-rich top layer that contains an excess of PSS [35,36]. However, conventional technologies not only involve a complicated process but also inevitably lower the work function (W.F.) of PEDOT:PSS when attempts are made to increase $\sigma$ because they include a process to remove the insulator-like PSS which is initially responsible for the outstanding W.F. properties of PEDOT:PSS, namely $~ 5.0 \mathrm{eV}[37,38]$. The lower W.F. is considered to be one of the reasons for the decrease in the PCE of fabricated HSCs because it gives rise to a large reverse saturation current density $\left(\mathrm{J}_{0}\right)$ and low open-circuit voltage $\left(\mathrm{V}_{\mathrm{oc}}\right)$ in the fabricated devices [39-41].

Moreover, as additional considerations for fabricating high-efficiency Si/PEDOT:PSS HSCs, it is also essential to form an effective Si surface passivation layer with hydrophilic properties. A layer such as this offers both an improved minority carrier lifetime $\left(\tau_{\text {eff }}\right)$ by lowering the defect density of the Si surface and ensures intimate contact between the spin-coated PEDOT:PSS and Si. The most widely used hydrophilic passivation layer for $\mathrm{Si}$ is a silicon oxide $\left(\mathrm{SiO}_{\mathrm{x}}\right)$, which can be either naturally grown [42] or chemically grown using a boiling $\mathrm{HNO}_{3}$ solution [43], dry $\mathrm{UV} / \mathrm{O}_{3}$ treatment, and ozonized deionized water [44]. This $\mathrm{SiO}_{x}$ layer improves the hydrophilicity and serves as a passivation layer for unsaturated Si bonds on the Si surface and thus enhances the properties of the interface of the Si/PEDOT:PSS HSC [43,45]. However, because effective external carrier extraction of the photo-generated carriers is a highly important pre-requisite for the efficiency of solar cells, the thickness of the $\mathrm{SiO}_{x}$ layer must remain less than $2 \mathrm{~nm}$ [46-48]. However, such a thin $\mathrm{SiO}_{\mathrm{x}}$ layer would provide limited passivation effect for $\mathrm{Si}$ surface defect states and is the origin of the short $\tau_{\text {eff }}$ of photo-generated carriers in devices [49].

These shortcomings have motivated recent studies on Si surface passivation technology in which organic materials are actively being sought as replacements for conventional $\mathrm{SiO}_{\mathrm{x}}$. Passivation of the $\mathrm{Si}$ surface with organic materials is particularly advantageous because it would enable $\tau_{\text {eff }}$ to be extended even with simple low-temperature and low-cost passivation processes. Previous studies for Si surface passivation with organic materials such as quinhydrone [50], 9,10-phenanthrenequinone [51], 1-octadecene [52], polyethyleneimine (PEI) [53], polyvinyl alcohol (PVA), and poly(methyl methacrylate) (PMMA) [54] succeeded in significantly improving $\tau_{\text {eff }}$ by forming effective chemical bonds with the unsaturated $\mathrm{Si}$ atoms present on the Si surface.

The objective of this study was to improve the PCE of Si/PEDOT:PSS HSC by applying our novel technologies to improve the conductivity of PEDOT:PSS and to effectively passivate the Si surface with the organic monomer benzoquinone (BQ). As reported, we successfully improved the conductivity of PEDOT:PSS to the level of $937 \mathrm{~S} / \mathrm{cm}$ simply by mixing hydroquinone $(\mathrm{HQ})$, which acts as a proton donating agent, with the pristine PEDOT:PSS solution. Our approach obviated the need for the PSS-removal process, indicating that it would also eliminate the problem of lowering the W.F. associated with conventional methods. Therefore, utilization of our HQ method for HSC fabrication was expected to improve the short-circuit current $\left(\mathrm{J}_{\mathrm{sc}}\right)$ and open-circuit voltage $\left(\mathrm{V}_{\mathrm{oc}}\right)$ of the devices. Moreover, in an attempt to further increase the PCE, benzoquinone (BQ) was introduced for the effective surface passivation of $\mathrm{Si}$. In addition, the quality of the interface between $\mathrm{Si}$ and PEDOT:PSS, which would be induced by improving the wettability of PEDOT:PSS solution on the $\mathrm{Si}$ surface, would be enhanced. As a result, we successfully increased the PCE of the HSC to $10.6 \%$, an improvement of more than $30 \%$ compared to the PCE attained with conventional technology.

\section{Experimental Section}

\subsection{Preparation of PEDOT:PSS Solution}

The PEDOT:PSS (HQ-PEDOT:PSS) solution containing HQ was prepared as follows: pristine PEDOT:PSS (Clevious PH1000, Heraeus, Hanau, Germany) was filtered with a PTFE syringe filter (JET BIOFIL, $0.45 \mu \mathrm{m}$ ), after which the solution was stirred overnight. 
Then, $3 \mathrm{~mL}$ of the prepared pristine PEDOT:PSS solution was mixed with various amounts of HQ (99\%, Sigma Aldrich Burlington, MA, USA): $0.33 \mathrm{wt} \%, 0.67 \mathrm{wt} \%$, and $1.0 \mathrm{wt} \%$, respectively. The PEDOT:PSS (DMSO-PEDOT:PSS) solution containing DMSO was prepared by mixing $0.5 \mathrm{wt} \%$ of dimethyl sulfoxide (DMSO, JUNSEI, Tokyo, Japan) and $0.1 \mathrm{wt} \%$ of Triton X-100 (TX, DAEJUNG, Siheung, Korea) with pristine PEDOT:PSS as reported previously [55].

\subsection{Device Fabrication}

Double-side polished $n$-type $\mathrm{Si}(n$-Si) wafers with a resistivity of $1.7-2.3 \Omega \mathrm{cm},(100)$ orientation, and a thickness of $280 \mu \mathrm{m}$ were cut into pieces sized $2 \mathrm{~cm} \times 2 \mathrm{~cm}$ and cleaned with the aid of ultra-sonication in acetone, methyl alcohol, and distilled-water (DI-water), in that order, for $15 \mathrm{~min}$ each. Afterward, the wafers were additionally cleaned in an RCA solution containing a mixture of $\mathrm{Na}_{4} \mathrm{OH}, \mathrm{H}_{2} \mathrm{O}_{2}$, and DI-water in a volume ratio of 1:1:5 at a temperature of $80^{\circ} \mathrm{C}$ for $15 \mathrm{~min}$ to remove residual organic contaminants. Subsequently, the wafers were immersed in a dilute HF solution ( $1 \mathrm{vol} \%$ ) for $1 \mathrm{~min}$ to remove the unintended native oxide layer from the $\mathrm{Si}$ surface. To fabricate the $\mathrm{HSC}$ with the $\mathrm{SiO}_{\mathrm{x}}$ passivation layer, the HF-treated Si substrates were exposed to air at room temperature for $1 \mathrm{~h}$, as reported in the previous study [43]. The BQ passivation solution was prepared by dissolving $10 \mathrm{mM}$ benzoquinone (BQ, 99\% ACROS) in $500 \mathrm{~mL}$ of methyl alcohol (MeOH, 99.5\%, SAMCHUN Co., Seoul, Korea). Si surface passivation with BQ was accomplished by placing the HFcleaned $\mathrm{Si}$ substrates in a jig that is open on the one side and then immersed in a $\mathrm{BQ} / \mathrm{MeOH}$ solution at room temperature for $1 \mathrm{~h}$ to form the BQ passivation layer, following which the BQ-treated $\mathrm{Si}$ substrate was dried in a stream of $\mathrm{N}_{2}$. The prepared PEDOT:PSS solutions were spin-coated onto the $\mathrm{Si}$ surfaces on which the $\mathrm{SiO}_{\mathrm{x}}$ and $\mathrm{BQ}$ passivation layers had been formed at $4000 \mathrm{rpm}$ for $60 \mathrm{~s}$ followed by annealing at $170{ }^{\circ} \mathrm{C}$ for $10 \mathrm{~min}$. Then, using thermal evaporation, the metal electrodes were deposited under vacuum at $3.0 \times 10^{-6} \mathrm{mbar}$. The back electrode consisted of $\mathrm{Al}(200 \mathrm{~nm}) / \mathrm{LiF}(1 \mathrm{~nm})$ and a shadow mask was used to deposit a 200-nm-thick Ag grid to serve as the front electrode.

\subsection{Characterization}

The average sheet resistance value of the PEDOT:PSS TF was calculated after taking measurements at eight different locations per sample using a four-point probe system (CMTSR2000N, AIT Co., Ltd., Suwon, Korea). The thickness of the TFs was measured with a surface profilometer (Tencor P6, KLA, Milpitas, CA, USA) and was used to derive the electrical conductivity of the coated TFs. The surface morphology of the PEDOT:PSS TF was studied by capturing atomic force microscopy (AFM, MultiMode-V, Veeco, Plainview, NY, USA) images in the tapping mode. The PSS-to-PEDOT ratio of coated PEDOT:PSS were measured by X-ray photoelectron spectroscopy (XPS) in the range of 157-175 eV and the W.F. of each TF was obtained with ultra-violet photoelectron spectroscopy (UPS, ESCALAB 250XI, Thermo-Fisher Co., Waltham, MA, USA). The wettability of the PEDOT:PSS solution on the Si surface was measured with a contact angle measurement system (FM-40, KRUSS Ltd., Hamburg, Germany). The minority carrier lifetime of the samples was measured with a photo-conductance lifetime tester (WCT-120, Sinton Instrument, Boulder, CO, USA), and the PCE of the fabricated HSCs was evaluated under the simulated air mass (AM) $1.5 \mathrm{G}$ condition.

\section{Result \& Discussion}

\subsection{Fabrication of Si/PEDOT:PSS Heterojunction Solar Cells (HSCs)}

This report introduces our novel approach to fabricate Si/PEDOT:PSS HSCs that utilize the proton-donating agent, $\mathrm{HQ}$, to increase the conductivity $(\sigma)$ of PEDOT:PSS [56]. Based on this report, various amounts of HQ were mixed with the pristine PEDOT:PSS solution to investigate the optimal amount of HQ that would most improve the performance of the HSCs. Before fabricating the HSCs, the $\sigma$ of each of the HQ-PEDOT:PSS TFs was measured to observe the variation in $\sigma$ with the amount of $\mathrm{HQ}$, as shown in Figure 2a. As shown in the figure, $0.67 \mathrm{wt} \%$ of HQ resulted in the highest improvement in $\sigma$ of $936.8 \mathrm{~S} / \mathrm{cm}$. 
This improvement is attributed to the added HQ acting as an $\mathrm{H}^{+}$donor for PEDOT:PSS to induce effective phase separation between the PEDOT and PSS, which were initially bonded by ionic interaction, after transforming the PSS into PSSH to stabilize it as depicted in Figure $2 b$. This phase separation results in intensified $\pi-\pi$ stacking interaction between polymers of the same kind, and thus the delocalization of electrons in the orbitals to form more continuous conductive channels between the PEDOT units to ultimately improve $\sigma[57,58]$. However, with $1.0 \mathrm{wt} \% \mathrm{HQ}$, a conductivity decrease to $672.3 \mathrm{~S} / \mathrm{cm}$ was observed. This degradation with excess HQ was most probably caused by the limited HQ solubility in PEDOT:PSS solution which induced a weakened proton-donating effect that resulted in less PSSH formation [56].
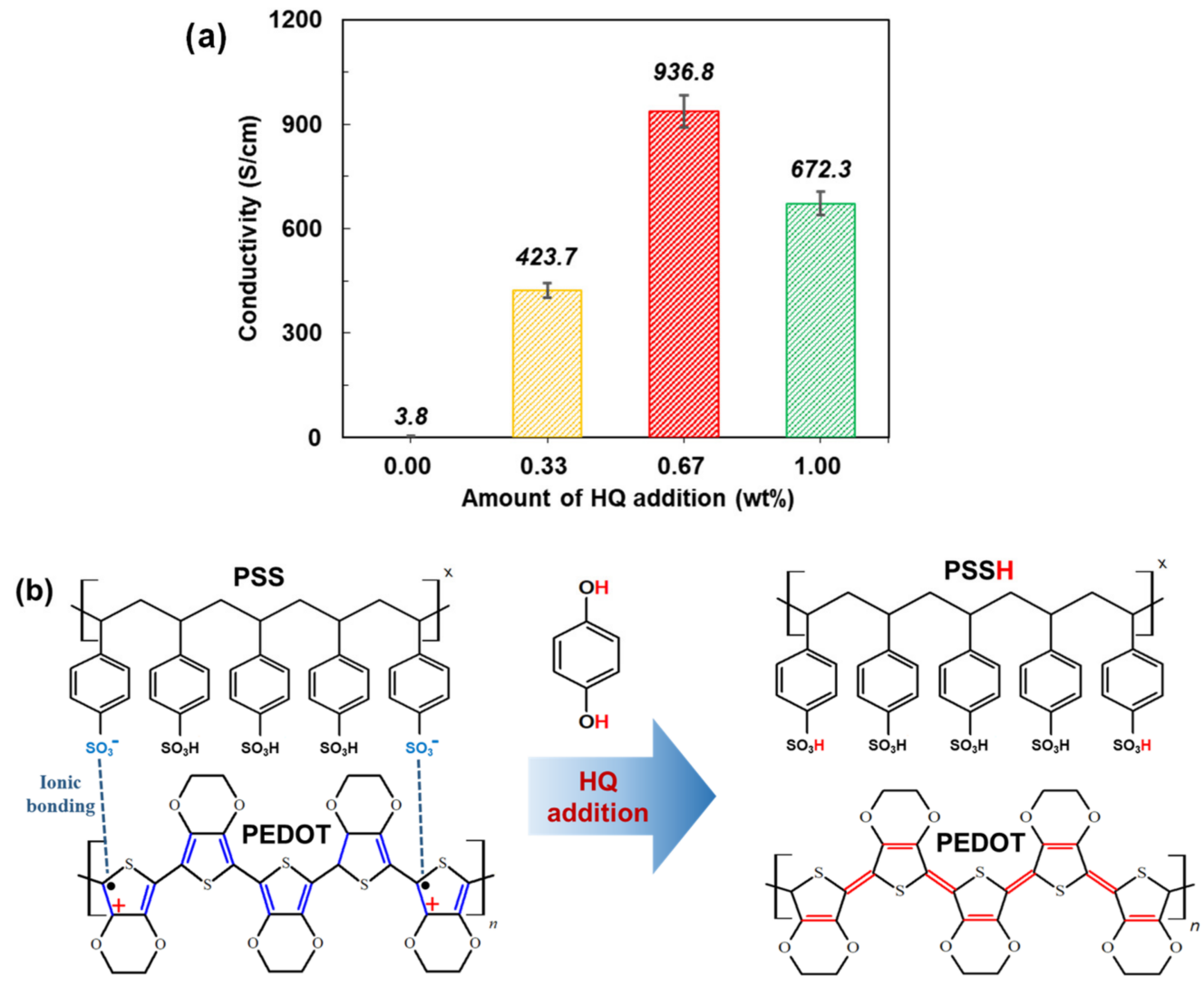

Figure 2. (a) Measured conductivity of PEDOT:PSS samples containing various amounts of HQ and (b) conformational change in the PEDOT:PSS structure after the addition of HQ.

The relationship between the HQ content and the performance of the fabricated HSCs was investigated by fabricating Si/HQ-PEDOT:PSS HSCs that contain various amounts of $\mathrm{HQ}$, as shown in Figure 3. Figure 3b shows the current density vs. voltage (J-V) curve for the fabricated HSCs, and Table 1 summarizes the PV performance parameters. The PCEs of the HSCs (HQ-HSCs) containing HQ were higher than those of the pristine-PEDOT:PSSbased HSCs (Pristine-HSC) in all cases. This increase in the PCE is considered to be a result of the increase in $\sigma$ of the HQ-PEDOT:PSS, as shown in a. However, as indicated in Table 1, we showed that the addition of HQ also dramatically improves the interfacial properties of $\mathrm{Si} / \mathrm{HQ}$-PEDOT:PSS because both the $\mathrm{V}_{\mathrm{oc}}$ and shunt resistance $\left(\mathrm{R}_{\mathrm{sh}}\right)$ were measured to have improved. The improved interfacial properties are considered to be the consequence of the re-distribution within the coated layer of PEDOT and PSS, which have low and high W.F. characteristics, respectively [59]. As reported by many researchers, during the process of depositing the PEDOT:PSS layer using spin coating, a PEDOT-rich layer forms at the bottom, and a PSS-rich layer forms at the top [31,60]. However, as discovered in our previous study, the addition of HQ to pristine PEDOT:PSS promotes phase separation between PEDOT and PSS. As a result, PEDOT is more uniformly and continuously redistributed within the 
coated TF with the simultaneous formation of improved charge carrier transport paths. In other words, the addition of HQ also ensures that PSS is more uniformly distributed, rather than being present in excess near the top surface because of the formation of a PSS-rich top layer. This indicates that the addition of HQ increases the amount of PSS that is present at the Si/PEDOT:PSS interface [56]. The increased presence of PSS with its high W.F. in close proximity to the $\mathrm{Si}$ surface induces increased built-in potential $\left(\mathrm{V}_{\mathrm{bi}}\right)$ after the formation of a contact between Si and PEDOT:PSS. Consequently, for the HSCs, we can expect: (1) reduced carrier recombination loss at the surface owing to enhanced field effect passivation and (2) increased $V_{o c}$ characteristics [40]. To confirm the re-distribution of PSS because of the presence of $\mathrm{HQ}$ to increase $\mathrm{V}_{\mathrm{bi}}$, we applied the current-voltage diode equation [Equation (S1)] to the measured J-V curves for the dark condition to extract the $V_{b i}$ values of the fabricated HSCs, as presented in Table S1. As indicated by the table, all the HQ-PEDOT:PSS samples were observed to exhibit significantly increased $V_{b i}$ values compared with those of the pristine-PEDOT:PSS. These results therefore enabled us to infer that the addition of HQ to pristine-PEDOT:PSS significantly increases not only the $\sigma$ of PEDOT:PSS itself but also the interfacial properties of Si/PEDOT:PSS. As a result, the PCE of the HQ-HSCs would be expected to dramatically improve compared with that of the pristine-HSCs, as was confirmed in Table 1. As shown in the table, the PCE of the HSC with $0.67 \mathrm{wt} \%$ of HQ improved the most to $8.8 \%$ from that of pristine-HSC of $2.5 \%$.

(a)

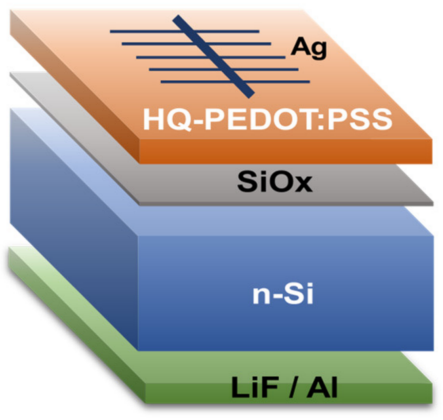

(b)

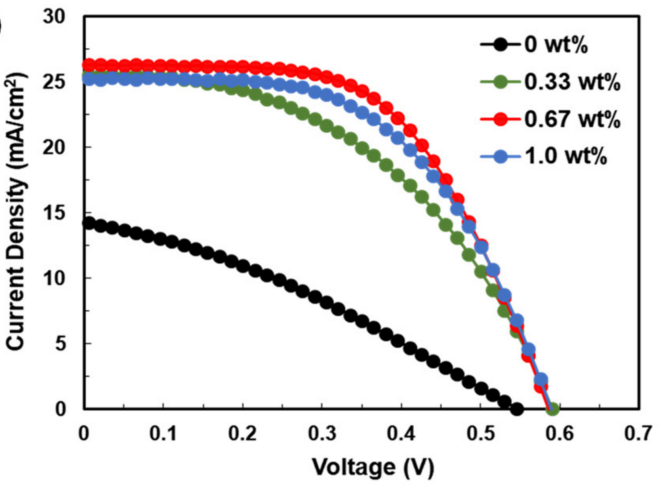

Figure 3. (a) Structure of the Si/HQ-PEDOT:PSS HSC and (b) current density vs. voltage characteristics of the various $\mathrm{Si} / \mathrm{HQ}-\mathrm{PEDOT}$ :PSS HSC samples with different HQ addition amounts.

Table 1. Photovoltaic parameters of Si/PEDOT:PSS HSCs containing various amounts of HQ.

\begin{tabular}{|c|c|c|c|c|c|c|}
\hline $\begin{array}{l}\text { Amount of } \\
\text { HQ Addition }\end{array}$ & $\begin{array}{c}\mathrm{J}_{\mathrm{sc}} \\
\left(\mathrm{mA} / \mathrm{cm}^{2}\right)\end{array}$ & $\begin{array}{l}\mathrm{V}_{\mathrm{oc}} \\
(\mathrm{mV})\end{array}$ & $\begin{array}{l}\text { FF } \\
(\%)\end{array}$ & $\begin{array}{c}R_{\mathrm{sh}} \\
\left(\Omega \cdot \mathrm{cm}^{2}\right)\end{array}$ & $\begin{array}{c}R_{\mathrm{s}} \\
\left(\Omega \cdot \mathrm{cm}^{2}\right)\end{array}$ & $\begin{array}{l}\text { PCE } \\
(\%)\end{array}$ \\
\hline $0 \mathrm{wt} \%$ & 14.3 & 547 & 32.0 & 113.5 & 28.1 & $\begin{array}{c}2.5 \\
\pm 0.93\end{array}$ \\
\hline $0.33 \mathrm{wt} \%$ & 25.6 & 590 & 47.1 & 504.8 & 6.8 & $\begin{array}{c}7.1 \\
\pm 0.60\end{array}$ \\
\hline $0.67 w t \%$ & 26.3 & 586 & 58.6 & 3680.9 & 6.1 & $\begin{array}{c}8.8 \\
\pm 0.44\end{array}$ \\
\hline $1.0 \mathrm{wt} \%$ & 25.3 & 589 & 55.1 & 1569.1 & 5.8 & $\begin{array}{c}8.2 \\
\pm 0.37\end{array}$ \\
\hline
\end{tabular}

\subsection{Comparison between HQ-PEDOT:PSS and Conventional DMSO-PEDOT:PSS}

In this study, to confirm the advantages of using HQ-PEDOT:PSS to improve the HSC performance compared with conventional technologies, DMSO was added to PEDOT:PSS (DMSO-PEDOT:PSS). This is the most widely used method to improve the $\sigma$ of PEDOT:PSS. Thus, a solution of DMSO-PEDOT:PSS was prepared and subsequently used to fabricate a $\mathrm{Si} /$ DMSO-PEDOT:PSS HSC (DMSO-HSC) to compare its performance with that of our HQHSCs. The measured J-V curves and detailed device parameters are presented in Figure 4 and Table 2, respectively. The results clearly show that replacing DMSO-PEDOT:PSS with 
HQ-PEDOT:PSS can increase the PCE by more than $10 \%$ from $7.7 \%$ to $8.8 \%$. However, Table 2 reveals that the increase in the PCE resulting from HQ-PEDOT:PSS could mainly be attributed to not only the increase in $\mathrm{J}_{\mathrm{sc}}$ (a result of the increased $\sigma$ ) but also to the increase in $V_{\text {oc }}$ and $R_{\text {sh }}$ which is consistent with the aforementioned HQ effect shown in Figure 3 and listed in Table 1.
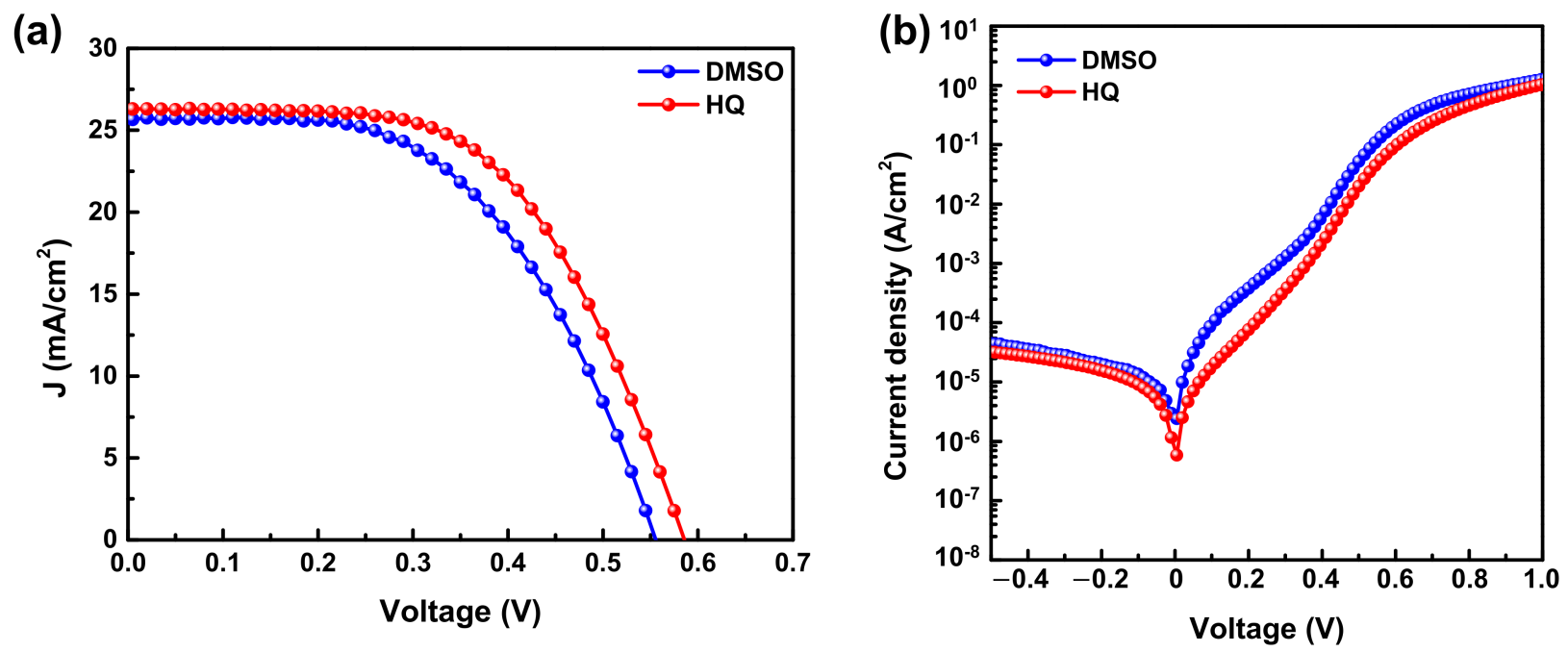

Figure 4. Current density vs. voltage curves of Si/PEDOT:PSS(DMSO, HQ) HSCs measured under (a) $100 \mathrm{~mW} / \mathrm{cm}^{2}$ illumination (AM1.5) and (b) dark conditions.

Table 2. Photovoltaic parameters of Si/PEDOT:PSS HSCs.

\begin{tabular}{ccccccc}
\hline PEDOT:PSS & $\begin{array}{c}\mathbf{J}_{\mathbf{s c}} \\
\left(\mathbf{m A} / \mathbf{c m}^{2}\right)\end{array}$ & $\begin{array}{c}\mathbf{V}_{\text {oc }} \\
(\mathbf{m V})\end{array}$ & $\begin{array}{c}\mathrm{FF} \\
\mathbf{( \% )}\end{array}$ & $\begin{array}{c}\mathbf{R}_{\mathbf{s h}} \\
\left(\mathbf{\Omega} \cdot \mathbf{c m}^{2}\right)\end{array}$ & $\begin{array}{c}\mathbf{R}_{\mathbf{s}} \\
\left(\mathbf{\Omega} \cdot \mathbf{c m}^{\mathbf{2}}\right)\end{array}$ & $\begin{array}{c}\mathbf{P C E} \\
(\mathbf{\%})\end{array}$ \\
\hline \multirow{2}{*}{ DMSO } & 25.7 & 556 & 53.8 & 1814.2 & 5.9 & $\begin{array}{c}7.7 \\
\pm 0.86\end{array}$ \\
& & & & & & 8.8 \\
HQ & 26.3 & 586 & 58.6 & 3680.2 & 6.1 & \pm 0.44 \\
\hline
\end{tabular}

We then compared the characteristics of the HQ- and DMSO-PEDOT:PSS TFs to clarify the reasons for the increased PCE with HQ-PEDOT:PSS compared to that of DMSOPEDOT:PSS. First, the $\sigma$ for each TF was measured and compared. As shown in Figure 5a, the $\sigma$ of DMSO-PEDOT:PSS was significantly higher at $733.7 \mathrm{~S} / \mathrm{cm}$ compared with that of pristine PEDOT:PSS $(3.8 \mathrm{~S} / \mathrm{cm})$, which is similar to the level of $\sigma$ in the previous report [33]. However, in the case of HQ-PEDOT:PSS, the $\sigma$ of $936.8 \mathrm{~S} / \mathrm{cm}$ was even higher than that of DMSO-PEDOT:PSS indicating that HQ increased the $\sigma$ of PEDOT:PSS by an even greater amount than the conventional approach with DMSO.

As mentioned above, the increase in $\sigma$ as a result of $\mathrm{HQ}$ is attributed to HQ acting as a proton-donating agent to PSS to promote the reduction of PSS to PSSH followed by the breakdown of the core-shell structure and ultimately by formation of more continuous linear-PEDOT domain within the TFs as depicted in Figure 5b [56]. However, on the basis of many previous studies, it is well known that, as a polar solvent, upon addition to pristine-PEDOT:PSS, DMSO would be placed between the PEDOT and PSS and would weaken the ionic interaction between them [61]. Therefore, the breakdown of the coreshell structure resulting from the presence of DMSO would also be expected to produce enhanced conductive-PEDOT continuity. We used AFM to analyze the surface morphology to compare HQ- and DMSO-PEDOT:PSS in terms of the extent to which the core-shell structure is broken down. In Figure 5c, the core-shell structure of the pristine PEDOT:PSS appears as islands of entangled bright regions [35]. However, the addition of DMSO (Figure 5d) and HQ (Figure 5e) significantly diminished the size of the islands and they 
became more uniformly and continuously distributed. However, in comparison, the degree of breakdown of the core-shell structure was more prominent for HQ-PEDOT:PSS. This is consistent with the results of the $\sigma$ measurement shown in Figure 5a. Moreover, the comparison of the surface roughness (RMS) revealed the RMS of HQ-PEDOT:PSS to be 1.27 , which is lower than the 1.77 of DMSO-PEDOT:PSS, confirming that HQ also provides a more uniform surface.

(a)

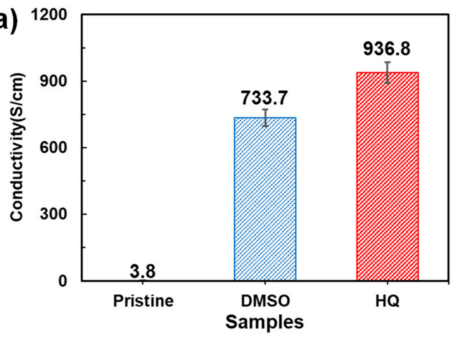

(b)

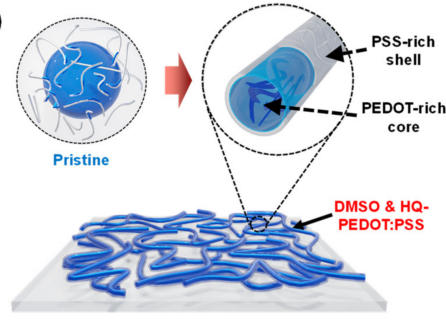

\section{(c)}
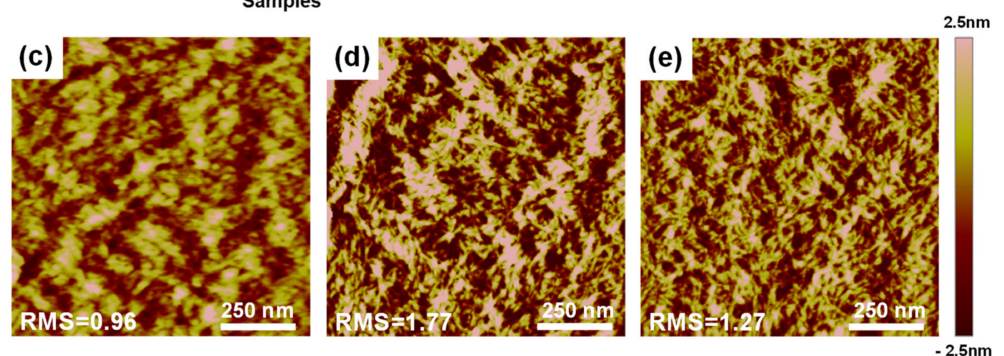

Figure 5. (a) Conductivity of various PEDOT:PSS TFs, and (b) schematic illustration of the HQ and DMSO effect on core-shell structure breakdown for continuous PEDOT conductive channel formation. AFM images of (c) pristine- (d) DMSO- and (e) HQ-PEDOT:PSS (scan size: $1 \mu \mathrm{m} \times 1 \mu \mathrm{m}$ ).

A more in-depth analysis of the increased PCE of HQ-HSC was carried out by additionally conducting XPS and UPS analyses to investigate the change in the PSS-to-PEDOT ratio and the effect on the W.F. of various PEDOT:PSS TFs. The XPS results are shown in Figure 6. As shown in Figure 6a, the S (2p) "curve" of pristine PEDOT:PSS comprises a spin-split doublet attributed to $S\left(p_{1 / 2,3 / 2}\right)$. The energy difference between the two peaks of the doublet is $1.18 \mathrm{eV}$, and the relative intensity between the doublets is known to be 1:2. In that case, the two peaks between 162 and $166 \mathrm{eV}$ are spin-split doublets attributed to the sulfur atom in PEDOT, and the two peaks between 166 and $172 \mathrm{eV}$ represent the sulfur atom in PSS [53,54]. Therefore, we calculated the area under the peaks of the binding energies using the $S(2 p)$ XPS results and compared the PSS-to-PEDOT ratio in DMSO- and HQ-PEDOT:PSS to analyze the change in the PSS-to-PEDOT ratio in each TF. The PSS-toPEDOT ratio of the pristine-PEDOT:PSS (i.e., PH1000) used in our study is known to be 2.5 and we obtained a similar level of 2.45, as shown in Figure 6a. However, the addition of DMSO significantly decreases the value to 2.16 , indicating that DMSO lowers the PSS ratio in the TF. This phenomenon was reported to commonly occur in many previous studies. This decrease in the PSS ratio occurs because the conventional approaches improve the $\sigma$ of PEDOT:PSS by partly removing the insulator-like PSS during the deposition process. As a result, the ratio of conductive PEDOT in the coated TF increases [62,63]. This is because a polar solvent such as DMSO would provide a screening effect and would weaken the ionic interaction between PEDOT and PSS to promote the separation of PSS from PEDOT and induce the partial removal of PSS during spin coating [62,64]. 

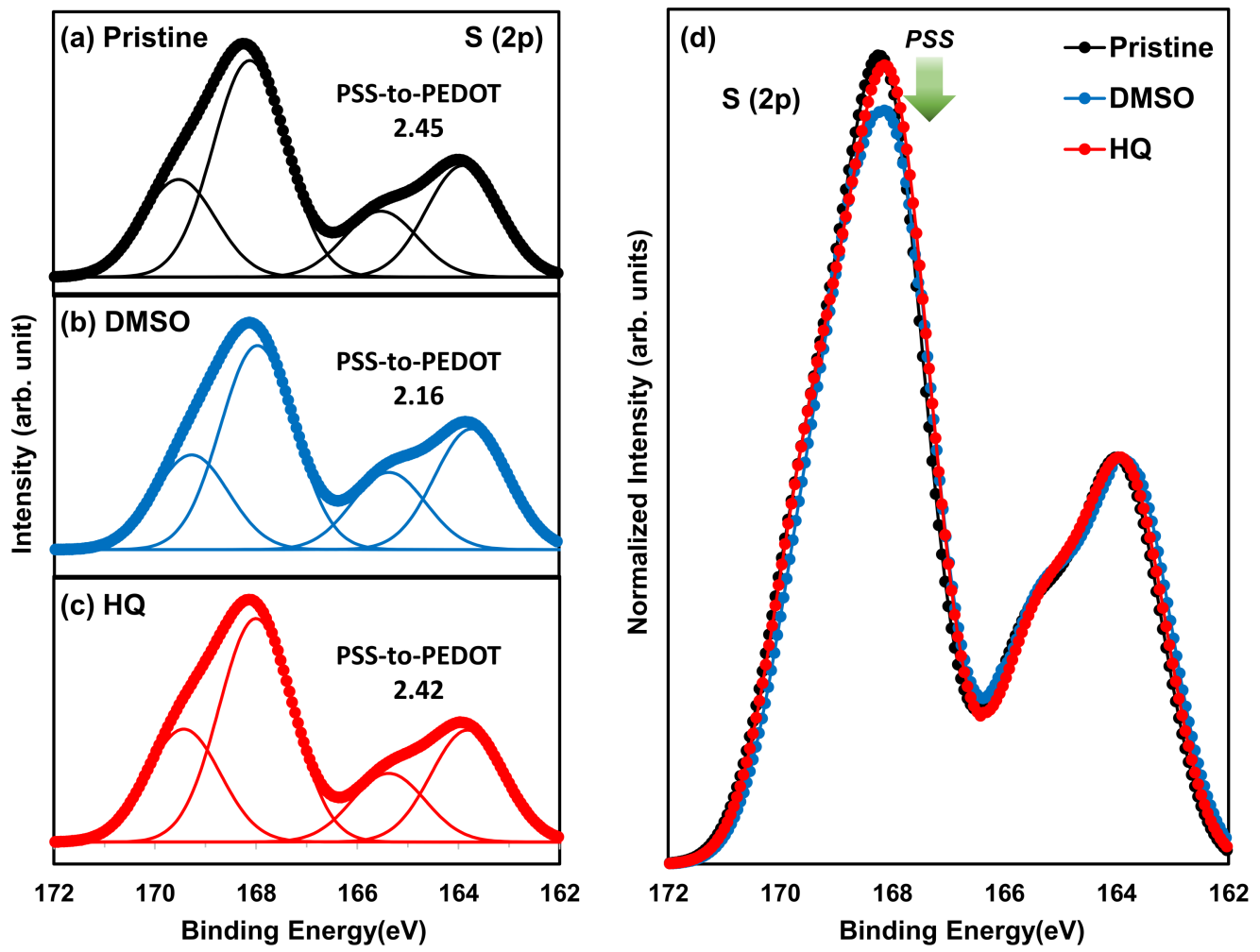

Figure 6. S (2p) XPS results of PEDOT:PSS: (a) pristine (b) DMSO (c) HQ and (d) relative comparison of peak intensities.

However, as shown in Figure 6c, the PSS-to-PEDOT ratio of HQ-PEDOT:PSS remains at 2.42 , which is only a minor change from the 2.45 of pristine PEDOT:PSS. This minor change strongly indicates that $\mathrm{HQ}$ enables more effective conductive channel formation in the PEDOT:PSS TF than DMSO even without the removal of PSS. This suggests that well-sustained high W.F. characteristics would be expected for PEDOT:PSS even with highly improved $\sigma[39,65]$. To confirm this, UPS measurements were recorded to compare the change in the W.F. of PEDOT:PSS TFs according to the degree of PSS removal, as shown in Figure 7. Based on the measured UPS results, a W.F. of $4.99 \mathrm{eV}$ was measured for pristine-PEDOT:PSS, which is very close to its value of $5.0 \mathrm{eV}[37,38]$. However, the W.F. of DMSO-PEDOT:PSS was $4.87 \mathrm{eV}$, which is $0.12 \mathrm{eV}$ lower than that of pristine PEDOT:PSS. In contrast, the W.F. of HQ-PEDOT:PSS was measured to be $4.98 \mathrm{eV}$, showing little change as expected. This high W.F. of HQ-PEDOT:PSS could be responsible for the higher PCE of our fabricated HSC (Table 2). Furthermore, the fill factor (FF) is expected to increase because of the high $\mathrm{V}_{\mathrm{oc}}$ characteristics in addition to the more effective field effect passivation of the Si surface compared with that of DMSO-HSC. 
(a)

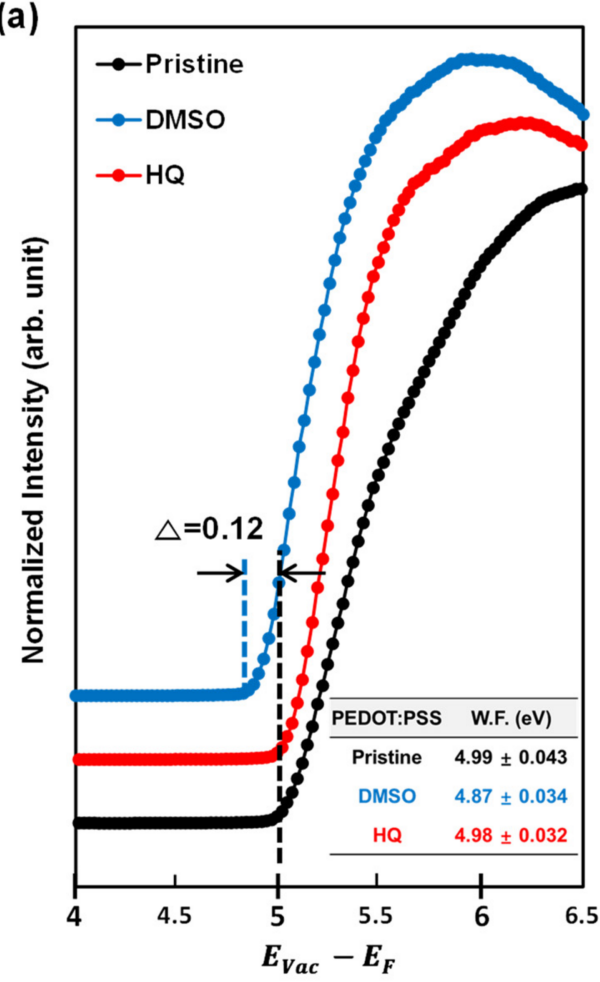

(b)
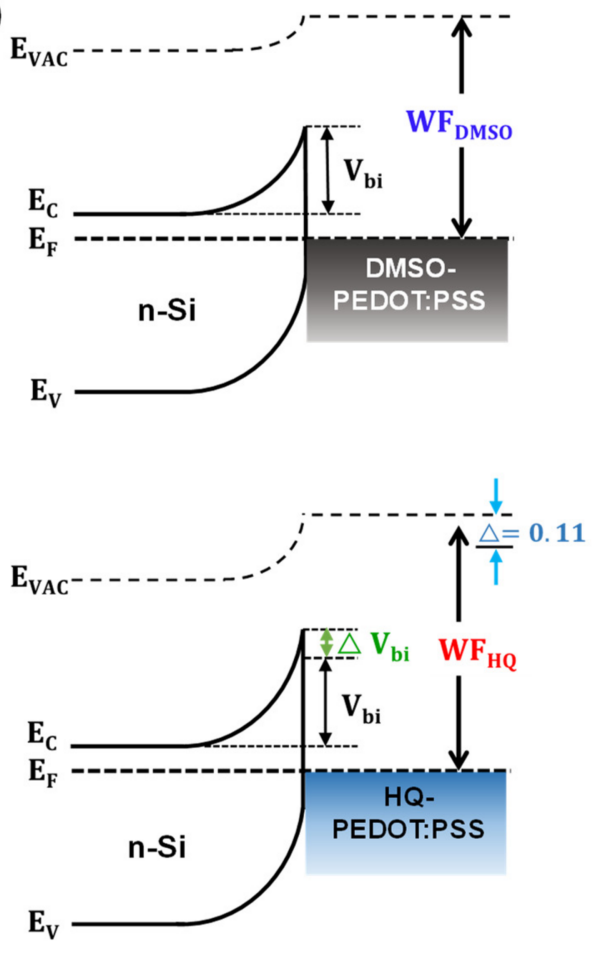

Figure 7. UPS results: (a) UPS secondary cut-off region and measured work function (W.F.) values and (b) energy diagram of cells based on the $n$-Si/PEDOT:PSS(DMSO, HQ) interface.

\section{3. n-Si/HQ-PEDOT:PSS Interface Engineering with Benzoquinone}

Apart from the high $\sigma$ of PEDOT:PSS, the properties of the Si/PEDOT:PSS interface are another crucial parameter to take into account when aiming to fabricate high-efficiency HSCs. Therefore, we also considered ways in which to improve the poor interface properties of Si/PEDOT:PSS. This made it necessary to consider two factors: (1) the formation of a passivation layer for excessive Si surface defect states and (2) improvement of the wettability of the PEDOT:PSS solution on the Si surface. Towards this purpose, we developed the technology to introduce benzoquinone (BQ) for Si surface passivation during HSC fabrication [66]. Figure 8 depicts the use of BQ to passivate the unsaturated-Si atoms on the Si surface. As shown in Figure 8a, BQ acts as an oxidation agent for $\mathrm{MeOH}$ when mixed with this solvent and transforms one of the carbonyl groups of $\mathrm{BQ}$ into a hydroxyl $\mathrm{O}-\mathrm{H}$ group by acquiring a $\mathrm{H}^{+}$from $\mathrm{MeOH}$. $\mathrm{BQ}$ is then transformed into the semiquinone (SQ) molecule [66,67]. Upon immersion of the HF-cleaned Si substrate into the prepared $\mathrm{BQ} / \mathrm{MeOH}$ passivation solution containing these SQ molecules, Si-SQ bonds are formed between unsaturated-Si atoms on the Si surface and the oxygen atom with an unpaired electron of SQ, as shown in Figure 8b. The formation of Si-SQ bonds basically provides a chemical passivation for the defect states on the Si surface. Moreover, as proven in our previous study, the Si-SQ bond also results in the formation of an intramolecular dipole moment owing to the difference in polarity between the $\mathrm{O}-\mathrm{H}$ group and the oxygen atoms present at both ends of SQ. This arrangement induces upward band bending at the $\mathrm{Si}$ surface, as shown in Figure 8c [66]. This upward band-bending with SQ can lead to an imbalance in the carrier concentration between electrons and holes on the Si surface, eventually lowering the surface recombination velocity and thus providing effective field effect passivation for the Si surface. 
(a)<smiles>CO[C@H](C)OCCOc1ccc(O)cc1</smiles>

(b)<smiles>Oc1ccc(Oc2ccc(O)cc2)cc1</smiles>

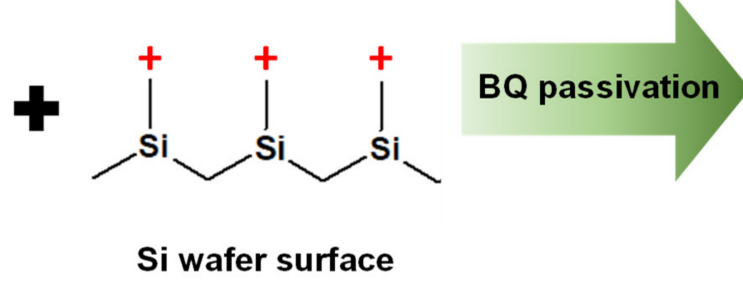

(c)

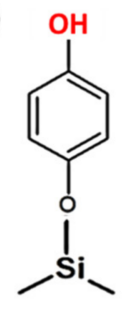

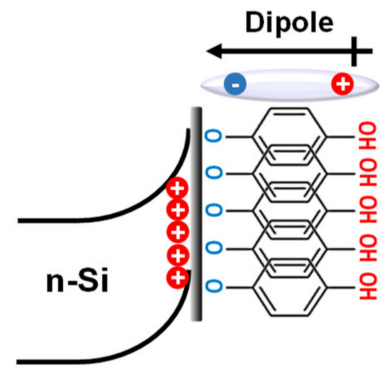

Figure 8. (a) Reduction reaction of $\mathrm{BQ}$ to form $\mathrm{SQ}$, (b) schematic illustration of $\mathrm{SQ}$ passivation on $\mathrm{Si}$ surface, and (c) energy alignment of SQ molecules on $n$-Si surface.

Therefore, treatment of the Si surface with BQ can both lower the surface defect density and the carrier concentration on the surface, thereby decreasing the photo-generated carrier loss owing to the Shockley-Read-Hall recombination ( $\left.\mathrm{R}_{\mathrm{SRH}}\right)$, as expressed by Equation (1) below. As a result, the minority carrier lifetime $\left(\tau_{\text {eff }}\right)$ within the devices could be expected to dramatically improve [68]:

$$
\mathrm{R}_{\mathrm{SRH}}=\left(\mathrm{n}_{\mathrm{s}} \mathrm{p}_{\mathrm{s}}-\mathrm{n}_{\mathrm{i}}^{2}\right) \mathrm{v}_{\mathrm{th}} \times \int_{\mathrm{E}_{\mathrm{v}}}^{\mathrm{E}_{\mathrm{c}}} \frac{\mathrm{D}\left(\mathrm{E}_{\mathrm{t}}\right)}{\left(\mathrm{n}_{\mathrm{s}}+\mathrm{n}_{1}\right) / \sigma_{\mathrm{p}}\left(\mathrm{E}_{\mathrm{t}}\right)+\left(\mathrm{p}_{\mathrm{s}}+\mathrm{p}_{1}\right) / \sigma_{\mathrm{n}}\left(\mathrm{E}_{\mathrm{t}}\right)} d \mathrm{E}_{\mathrm{t}}
$$

where $\mathrm{n}_{1}$ and $\mathrm{p}_{1}$ refer to the density of electrons and holes in the bulk, $\mathrm{n}_{\mathrm{s}}$ and $\mathrm{p}_{\mathrm{s}}$ are the density of electrons and holes on the surface, $\mathrm{v}_{\text {th }}$ represents the thermal velocity, $\mathrm{E}_{\mathrm{C}}$ and $E_{V}$ refer to the conduction and valance band energies, $D_{i t}$ represents the density of interface states, and $\sigma_{\mathrm{n}}$ and $\sigma_{\mathrm{p}}$ are the energy-dependent capture cross sections for holes and electrons.

To compare the Si surface passivation efficiency of our BQ passivation method with that of the conventional native oxide approach, we measured the $\tau_{\text {eff }}$ for $B Q$ and native oxide formed Si samples by fabricating the sandwich structures shown in Figure 9a. As a result, as shown in Figure 9b, BQ passivation yielded $\tau_{\text {eff }}$ of $133 \mu \mathrm{s}$, which is three times higher than that of the sample passivated by the native oxide. This confirmed that $B Q$ treatment would considerably increase the passivation efficiency of a surface with excess $\mathrm{Si}$ defect states.

Additionally, it was also confirmed that the formation of Si-SQ bonds with BQ could improve the hydrophilicity of the Si surface. The results of the contact angle measurements are shown in Figure 10. These measurements were conducted to compare the wettability of the HQ-PEDOT:PSS solution between the BQ treated and native oxide formed Si surfaces. The results indicate that, the Si surface, on which the SQ layer is formed, has a smaller contact angle of $48.6^{\circ}$ (Figure 10d) compared to $56.6^{\circ}$ (Figure 10c) of the native oxide formed $\mathrm{Si}$ surface. The improved hydrophilicity is the result of the hydrophilic $\mathrm{O}-\mathrm{H}$ group on the Si surface when the Si-SQ bond is formed, as depicted in Figure 8c [69,70]. 
(a)

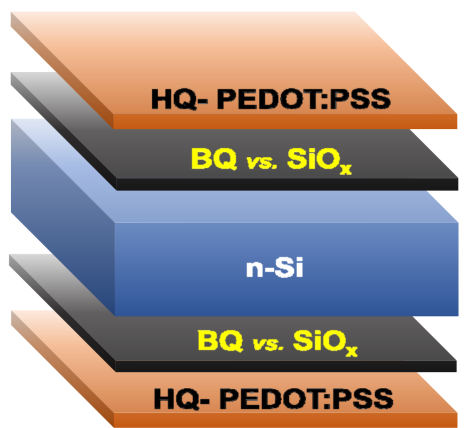

(b)

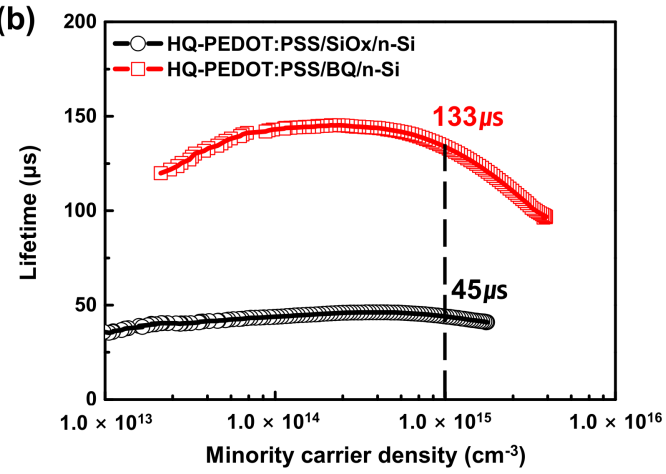

Figure 9. (a) The structure used to measure the lifetime and (b) carrier injection-dependent lifetime of HQ-PEDOT:PSS on silicon wafers with the different surface passivation layers.

\section{(a) Pristine-PEDOT:PSS}

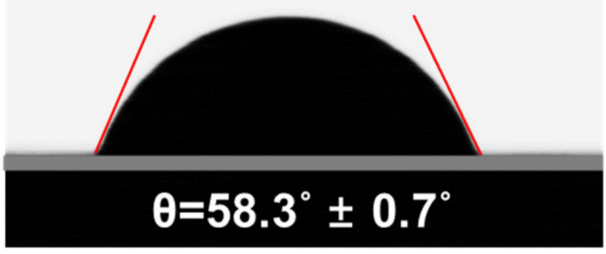

\section{(c) HQ-PEDOT:PSS}

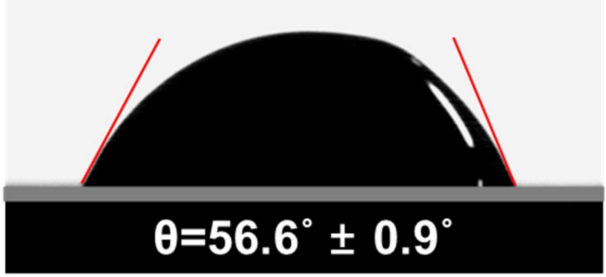

(b) DMSO-PEDOT:PSS

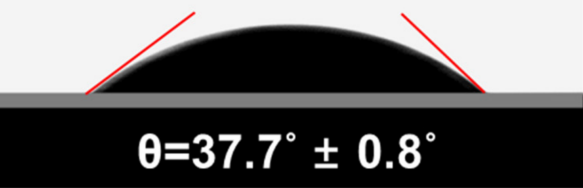

(d) BQ \& HQ-PEDOT:PSS

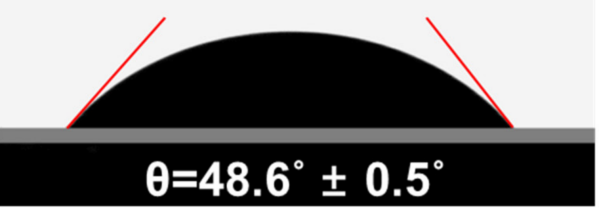

Figure 10. Measured contact angles of (a) pristine-, (b) DMSO-, (c) HQ-PEDOT:PSS on the native oxide formed Si surface, and (d) HQ-PEDOT:PSS on the BQ treated Si surface.

To evaluate the increase in the PCE of the HQ-HSC treated with BQ, the device characteristics of HSCs with and without BQ treatment were evaluated, and the results are presented in Figure 11 and Table 3. The results in the table confirmed that BQ treatment notably increased the PCE of the fabricated HSC to $10.6 \%$, which is more than $20 \%$ higher than that of the HSC with the native oxide. We consider this PCE improvement to be dominantly affected by: (1) the improved parasitic resistance $\left(R_{s h}\right.$ and $\left.R_{s}\right)$ that originated from the formation of the hydrophilic SQ passivation layer and (2) higher $V_{o c}$ resulting from the increased $V_{b i}$ (i.e., $\Delta \mathrm{V}_{\mathrm{bi}}^{\mathrm{SQ}}$ ) with the formation of a dipole moment with the SQ layer, as schematically illustrated in Figure $11 b[67,71]$. To confirm that the increase in the $V_{b i}$ was a consequence of the $B Q$ treatment, we extracted $\mathrm{V}_{\mathrm{bi}}$ from the measured dark J-V characteristics for the fabricated HSCs as presented in Table S3. The results reveal a higher $\mathrm{V}_{\mathrm{bi}}$ for the BQ-treated HSC (BQ-HSC), $693 \mathrm{mV}$, compared to that of the native oxide formed HSC ( $\left.\mathrm{SiO}_{\mathrm{x}}-\mathrm{HSC}\right), 661 \mathrm{mV}$. The results in Table S3, obtained by calculation with the diode equation, show that $\mathrm{V}_{\mathrm{bi}}$ increases during the formation of the SQ passivation layer. This indicates that SQ passivation would lower $\mathrm{J}_{0}$ by decreasing the $\mathrm{R}_{\mathrm{SRH}}$ loss (i.e., by decreasing the ideality factor, $\mathrm{n}$ ) as shown in Table S3. Therefore, the BQ treatment introduced in this study can dramatically enhance the properties of the Si/PEDOT:PSS interface. 
(a)

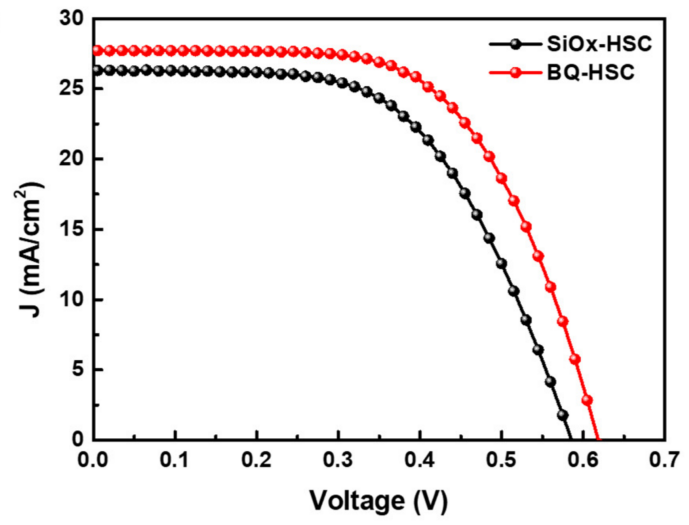

(b)

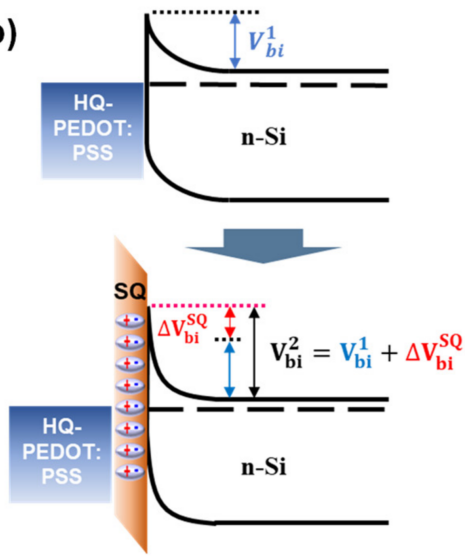

Figure 11. (a) Current density vs. voltage curves of $\mathrm{SiO}_{\mathrm{x}}-\mathrm{HSC}$ and $\mathrm{BQ}-\mathrm{HSC}$ measured under $100 \mathrm{~mW} / \mathrm{cm}^{2}$ illumination (AM1.5) and (b) effect of interface dipole formation with BQ passivation of the Si surface.

Table 3. Photovoltaic parameters of $\mathrm{SiO}_{\mathrm{x}}$-HSC and BQ-HCS.

\begin{tabular}{ccccccc}
\hline Passivation & $\begin{array}{c}\mathbf{J}_{\mathbf{s c}} \\
\left(\mathbf{m A} / \mathbf{c m}^{2}\right)\end{array}$ & $\begin{array}{c}\mathbf{V}_{\mathbf{o c}} \\
(\mathbf{m V})\end{array}$ & $\begin{array}{c}\mathbf{F F} \\
(\mathbf{\%})\end{array}$ & $\begin{array}{c}\mathbf{R}_{\mathbf{s h}} \\
\left(\boldsymbol{\Omega} \cdot \mathbf{c m}^{2}\right)\end{array}$ & $\begin{array}{c}\mathbf{R}_{\mathbf{s}} \\
\left(\mathbf{\Omega} \cdot \mathbf{c m}^{2}\right)\end{array}$ & $\begin{array}{c}\mathbf{P C E} \\
(\mathbf{\%})\end{array}$ \\
\hline SiOx-HSC & 26.3 & 586 & 58.6 & 3680.2 & 6.1 & $\begin{array}{c}8.8 \\
\end{array}$ \\
BQ-HSC & 27.7 & 618 & 61.8 & 4855.3 & 4.6 & $\begin{array}{c}1.36 \\
\pm 1.6\end{array}$ \\
\hline
\end{tabular}

\section{Conclusions}

This report presents our novel technologies to improve the conductivity of PEDOT:PSS. Then, the properties of the Si/PEDOT:PSS interface were applied to fabricate a Si/PEDOT:PSS HSC with the ultimate objective of increasing the PCE. We successfully demonstrated that HQ-PEDOT:PSS can significantly improve the device performance compared to conventional approaches. Detailed analyses of the fabricated HSC and PEDOT:PSS TFs confirmed that the PCE improvement originated from the high $\sigma$ and high W.F. of HQ-PEDOT:PSS. These improved properties were induced by the formation of effective charge transport paths within the conductive PEDOT and because the insulator-like PSS was not removed. In addition, we also showed that $\mathrm{BQ}$ treatment of the Si surface can produce an SQ layer on the surface after forming Si-SQ bonds. This layer not only acts as an effective passivation layer for Si surface defect states but also induces upward band-bending on the $\mathrm{Si}$ surface followed by a significant improvement of the properties of the Si/PEDOT:PSS interface. The use of these two approaches with HQ and BQ increased the PCE of the HSCs to $10.6 \%$, an improvement of more than $20 \%$ compared to that achieved with the conventional approaches. We consider the HQ-PEDOT:PSS and BQ surface treatment technologies introduced in this study to provide an important foundation for developing low-cost and high-efficiency Si / PEDOT:PSS HSCs owing to their simple but highly effective processes whereby both the electrical properties of PEDOT:PSS and the interface properties of $\mathrm{Si} /$ PEDOT:PSS are improved.

Supplementary Materials: The following supporting information can be downloaded at: https: / / www.mdpi.com/article/10.3390/polym14030478/s1, Figure S1: ln J-V curves measured in the dark condition for fabricated n-Si/HQ-PEDOT:PSS HSCs with various HQ addition amounts; Table S1: Summary of J0, n, and Vbi fitted parameters from the measured dark $\ln \mathrm{J}-\mathrm{V}$ curves of various amounts of Si/HQ-PEDOT:PSS HSCs; Table S2: Summary of J0, $\mathrm{n}$ and Vbi fitted parameters from the measured dark ln J-V curves of the Si PEDOT:PSS(DMSO, HQ) HSCs; Figure S2: Dark characteristics (a) Dark ln J-V curves, (b) d(V)/d(ln J) vs J plots and (c) H(J) vs J plots of the BQ-HSC and SiOx-HSC; Table S3: Summary of J0, n, and Vbi, fitted parameters from the measured dark $\ln \mathrm{J}-\mathrm{V}$ curves of the HSCs. 


\begin{abstract}
Author Contributions: Conceptualization, N.Y.P. and J.-Y.C..; methodology, G.S.J., Y.-J.Y., and Y.-C.J.; validation, N.Y.P., J.H.L.; formal analysis, N.Y.P., J.H.L., J.H.S., and J.-Y.C.; investigation, N.Y.P., J.H.S.; data curation, G.S.J., Y.-J.Y., Y.-C.J., and J.H.L.; writing—original draft preparation, N.Y.P.; writing—review and editing, J.-Y.C.; visualization, N.Y.P.; supervision, J.-Y.C.; project administration, J.-Y.C.; funding acquisition, J.-Y.C. All authors have read and agreed to the published version of the manuscript.
\end{abstract}

Funding: This work was supported by the National Research Foundation of Korea (NRF) grant funded by the Korea government (Ministry of Science and ICT) (2020R1F1A1053556) and the Busan Innovation Institute of Industry, Science \& Technology Planning(BISTEP) grant funded by the Busan Metropolitan City (Project Name: Open Laboratory Business Meeting Market Demands). This research was financially supported by the Ministry of SMEs and Startups through the Human Resource Training Project for Industry Matched R\&D (S2931417).

Institutional Review Board Statement: Not applicable.

Informed Consent Statement: Not applicable.

Conflicts of Interest: The authors declare no conflict of interest.

\title{
References
}

1. Wojciechowski, K.; Forgács, D.; Rivera, T. Industrial opportunities and challenges for perovskite photovoltaic technology. Solar RRL 2019, 3, 1900144. [CrossRef]

2. Sampaio, P.G.V.; González, M.O.A. Photovoltaic solar energy: Conceptual framework. Renew. Sustain. Energy Rev. 2017, 74, 590-601. [CrossRef]

3. Nazeeruddin, M.K. Twenty-five years of low-cost solar cells. Nature 2016, 538, 463-464. [CrossRef] [PubMed]

4. Hermle, M.; Feldmann, F.; Bivour, M.; Goldschmidt, J.C.; Glunz, S.W. Passivating contacts and tandem concepts: Approaches for the highest silicon-based solar cell efficiencies. Appl. Phys. Rev. 2020, 7, 021305. [CrossRef]

5. Wolden, C.A.; Kurtin, J.; Baxter, J.B.; Repins, I.; Shaheen, S.E.; Torvik, J.T.; Rockett, A.A.; Fthenakis, V.M.; Aydil, E.S. Photovoltaic manufacturing: Present status, future prospects, and research needs. J. Vac. Sci. Technol. A Vac. Surf. Films 2011, $29,030801$. [CrossRef]

6. Service, R.F. Can the Upstarts Top Silicon? Science 2008, 319, 718-720. [CrossRef]

7. Chen, D.; Chen, Y.; Wang, Z.; Gong, J.; Liu, C.; Zou, Y.; He, Y.; Wang, Y.; Yuan, L.; Lin, W. 24.58\% total area efficiency of screen-printed, large area industrial silicon solar cells with the tunnel oxide passivated contacts (i-TOPCon) design. Sol. Energy Mater. Sol. Cells 2020, 206, 110258. [CrossRef]

8. Li, M.; Dai, Y.; Ma, W.; Yang, B.; Chu, Q. Review of new technology for preparing crystalline Silicon solar cell materials by metallurgical method. In Earth and Environmental Science, Proceedings of the 3rd International Conference on Energy, Environment and Materials Science (EEMS 2017); Singapore, 28-30 July 2017, IOP Conference Series; IOP Publishing: Bristol, UK, 2017.

9. Srivastava, S.K.; Kumar, D.; Sharma, M.; Kumar, R.; Singh, P.K. Silver catalyzed nano-texturing of silicon surfaces for solar cell applications. Sol. Energy Mater. Sol. Cells 2012, 100, 33-38. [CrossRef]

10. Srivastava, S.K.; Kumar, D.; Singh, P.K.; Kumar, V. Silicon nanowire arrays based "black silicon" solar cells. In Proceedings of the 2009 34th IEEE Photovoltaic Specialists Conference (PVSC), Philadelphia, PA, USA, 7-12 June 2009; IEEE: Piscataway, NJ, USA, 2009.

11. Lee, Y.-T.; Lin, F.-R.; Chen, C.-H.; Pei, Z. A 14.7\% Organic/silicon nanoholes hybrid solar cell via interfacial engineering by solution-processed inorganic conformal layer. ACS Appl. Mater. Interfaces 2016, 8, 34537-34545. [CrossRef]

12. Yu, X.; Shen, X.; Mu, X.; Zhang, J.; Sun, B.; Zeng, L.; Yang, L.; Wu, Y.; He, H.; Yang, D. High efficiency organic/silicon-nanowire hybrid solar cells: Significance of strong inversion layer. Sci. Rep. 2015, 5, 17371. [CrossRef]

13. Yu, P.; Tsai, C.-Y.; Chang, J.-K.; Lai, C.-C.; Chen, P.-H.; Lai, Y.-C.; Tsai, P.-T.; Li, M.-C.; Pan, H.-T.; Huang, Y.-Y. 13\% efficiency hybrid organic/silicon-nanowire heterojunction solar cell via interface engineering. ACS Nano 2013, 7, 10780-10787. [CrossRef] [PubMed]

14. Tune, D.D.; Flavel, B.S.; Quinton, J.S.; Ellis, A.V.; Shapter, J.G. Single-Walled Carbon Nanotube/Polyaniline/n-Silicon Solar Cells: Fabrication, Characterization, and Performance Measurements. ChemSusChem 2013, 6, 320-327. [CrossRef] [PubMed]

15. Williams, E.L.; Jabbour, G.E.; Wang, Q.; Shaheen, S.E.; Ginley, D.S.; Schiff, E.A. Conducting polymer and hydrogenated amorphous silicon hybrid solar cells. Appl. Phys. Lett. 2005, 87, 223504. [CrossRef]

16. Baek, S.-W.; Jun, S.; Kim, B.; Proppe, A.H.; Ouellette, O.; Voznyy, O.; Kim., C.; Kim., J.; Walters, G.; Song, J.H. Efficient hybrid colloidal quantum dot/organic solar cells mediated by near-infrared sensitizing small molecules. Nat. Energy 2019, 4, 969-976. [CrossRef]

17. Lim, N.; Cho, N.; Paek, S.; Kim, C.; Lee, J.K.; Ko, J. High-performance organic solar cells with efficient semiconducting small molecules containing an electron-rich benzodithiophene derivative. Chem. Mater. 2014, 26, 2283-2288. [CrossRef]

18. Troshin, P.A.; Hoppe., H.; Renz, J.; Egginger, M.; Mayorova, J.Y.; Goryachev, A.E.; Peregudov, A.S.; Lyubovskaya, R.N.; Gobsch, G.; Sariciftci, N.S. Material solubility-photovoltaic performance relationship in the design of novel fullerene derivatives for bulk heterojunction solar cells. Adv. Funct. Mater. 2009, 19, 779-788. [CrossRef] 
19. Umeyama, T.; Imahori, H. Isomer effects of fullerene derivatives on organic photovoltaics and perovskite solar cells. Acc. Chem. Res. 2019, 52, 2046-2055. [CrossRef]

20. Huang, D.; Goh, T.; Kong, J.; Zheng, Y.; Zhao, S.; Xu, Z.; Taylor, A.D. Perovskite solar cells with a DMSO-treated PEDOT: PSS hole transport layer exhibit higher photovoltaic performance and enhanced durability. Nanoscale 2017, 9, 4236-4243. [CrossRef]

21. Pietsch, M.; Bashouti, M.Y.; Christiansen, S. The role of hole transport in hybrid inorganic/organic silicon/poly (3,4-ethylenedioxythiophene): Poly (styrenesulfonate) heterojunction solar cells. J. Phys. Chem. C 2013, 117, 9049-9055. [CrossRef]

22. Thomas, J.P.; Leung, K.T. Mixed co-solvent engineering of PEDOT: PSS to enhance its conductivity and hybrid solar cell properties. J. Mater. Chem. A 2016, 4, 17537-17542. [CrossRef]

23. Reza, K.M.; Gurung, A.; Bahrami, B.; Mabrouk, S.; Elbohy, H.; Pathak, R.; Chen, K.; Chowdhury, A.H.; Rahman, M.T.; Letourneau, S. Tailored PEDOT: PSS hole transport layer for higher performance in perovskite solar cells: Enhancement of electrical and optical properties with improved morphology. J. Energy Chem. 2020, 44, 41-50. [CrossRef]

24. Kim, Y.H.; Sachse, C.; Machala, M.L.; May, C.; Müller-Meskamp, L.; Leo, K. Highly conductive PEDOT: PSS electrode with optimized solvent and thermal post-treatment for ITO-free organic solar cells. Adv. Funct. Mater. 2011, 21, 1076-1081. [CrossRef]

25. Zhu, Y.; Song, T.; Zhang, F.; Lee, S.-T.; Sun, B. Efficient organic-inorganic hybrid Schottky solar cell: The role of built-in potential. Appl. Phys. Lett. 2013, 102, 113504. [CrossRef]

26. Snaith, H.J.; Kenrick, H.; Chiesa, M.; Friend, R.H. Morphological and electronic consequences of modifications to the polymer anode 'PEDOT: PSS'. Polymer 2005, 46, 2573-2578. [CrossRef]

27. Huang, J.; Miller, P.F.; de Mello, J.C.; de Mello, A.J.; Bradley, D.D.C. Influence of thermal treatment on the conductivity and morphology of PEDOT/PSS films. Synth. Met. 2003, 139, 569-572. [CrossRef]

28. Friedel, B.; Keivanidis, P.E.; Brenner, T.J.K.; Abrusci, A.; McNeill, C.R.; Friend, R.H.; Greenham, N.C. Effects of layer thickness and annealing of PEDOT: PSS layers in organic photodetectors. Macromolecules 2009, 42, 6741-6747. [CrossRef]

29. Song, C.; Zhong, Z.; Hu, Z.; Luo, Y.; Wang, L.; Wang, J.; Cao, Y. The effect of solvent treatment on the buried PEDOT: PSS layer. Org. Electron. 2017, 43, 9-14. [CrossRef]

30. Zhang, X.; Wu, J.; Wang, J.; Zhang, J.; Yang, Q.; Fu, Y.; Xie, Z. Highly conductive PEDOT: PSS transparent electrode prepared by a post-spin-rinsing method for efficient ITO-free polymer solar cells. Sol. Energy Mater. Sol. Cells 2016, 144, 143-149. [CrossRef]

31. Lang, U.; Müller, E.; Naujoks, N.; Dual, J. Microscopical investigations of PEDOT: PSS thin films. Adv. Funct. Mater. 2009, 19, 1215-1220. [CrossRef]

32. Nardes, A.M.; Kemerink, M.; Janssen, R.A.J.; Bastiaansen, J.A.M.; Kiggen, N.M.M.; Langeveld, B.M.W.; Van Breemen, A.J.J.M.; De Kok, M.M. Microscopic understanding of the anisotropic conductivity of PEDOT: PSS thin films. Adv. Mater. 2007, 19, 1196-1200. [CrossRef]

33. Yan, F.; Parrott, E.P.J.; Ung, B.S.-Y.; Pickwell-MacPherson, E. Solvent doping of PEDOT/PSS: Effect on terahertz optoelectronic properties and utilization in terahertz devices. J. Phys. Chem. C 2015, 119, 6813-6818. [CrossRef]

34. Nevrela, J.; Micjan, M.; Novota, M.; Kovacova, S.; Pavuk, M.; Juhasz, P.; Kovac, J., Jr.; Jakabovic, J.; Weis, M. Secondary doping in poly (3, 4-ethylenedioxythiophene): Poly (4-styrenesulfonate) thin films. J. Polym. Sci. Part B Polym. Phys. 2015, 53, 1139-1146. [CrossRef]

35. Chou, T.-R.; Chen, S.-H.; Chiang, Y.-T.; Lin, Y.-T.; Chao, C.-Y. Highly conductive PEDOT: PSS films by post-treatment with dimethyl sulfoxide for ITO-free liquid crystal display. J. Mater. Chem. C 2015, 3, 3760-3766. [CrossRef]

36. McCarthy, J.E.; Hanley, C.A.; Brennan, L.J.; Lambertini, V.G.; Gun'ko, Y.K. Fabrication of highly transparent and conducting PEDOT: PSS films using a formic acid treatment. J. Mater. Chem. C 2014, 2, 764-770. [CrossRef]

37. Ouyang, J. "Secondary doping" methods to significantly enhance the conductivity of PEDOT: PSS for its application as transparent electrode of optoelectronic devices. Displays 2013, 34, 423-436. [CrossRef]

38. Yin, L.; Zhao, Z.; Jiang, F.; Li, Z.; Xiong, S.; Zhou, Y. PEDOT: PSS top electrode prepared by transfer lamination using plastic wrap as the transfer medium for organic solar cells. Org. Electron. 2014, 15, 2593-2598. [CrossRef]

39. Lee, J.J.; Lee, S.H.; Kim, F.S.; Choi, H.H.; Kim, J.H. Simultaneous enhancement of the efficiency and stability of organic solar cells using PEDOT: PSS grafted with a PEGME buffer layer. Org. Electron. 2015, 26, 191-199. [CrossRef]

40. Na, S.-I.; Wang, G.; Kim, S.-S.; Kim, T.-W.; Oh, S.-H.; Yu, B.-K.; Lee, T.; Kim, D.-Y. Evolution of nanomorphology and anisotropic conductivity in solvent-modified PEDOT: PSS films for polymeric anodes of polymer solar cells. J. Mater. Chem. 2009, 19, 9045-9053. [CrossRef]

41. Lee, T.W.; Chung, Y. Control of the surface composition of a conducting-polymer complex film to tune the work function. Adv. Funct. Mater. 2008, 18, 2246-2252. [CrossRef]

42. Thomas, J.P.; Zhao, L.; Abd-Ellah, M.; Heining, N.F.; Leung, K.T. Interfacial micropore defect formation in PEDOT: PSS-Si hybrid solar cells probed by TOF-SIMS 3D chemical imaging. Anal. Chem. 2013, 85, 6840-6845. [CrossRef]

43. Sheng, J.; Fam, K.; Wang, D.; Han, C.; Fang, J.; Gao, P.; Ye, J. Improvement of the SiO x passivation layer for high-efficiency Si/PEDOT: PSS heterojunction solar cells. ACS Appl. Mater. Interfaces 2014, 6, 16027-16034. [CrossRef] [PubMed]

44. Moldovan, A.; Feldmann, F.; Kaufmann, K.; Richter, S.; Werner, M.; Hagendorf, C.; Zimmer, M.; Rentsch, J.; Hermle, M. Tunnel oxide passivated carrier-selective contacts based on ultra-thin $\mathrm{SiO}_{2}$ layers grown by photo-oxidation or wet-chemical oxidation in ozonized water. In Proceedings of the 2015 IEEE 42nd Photovoltaic Specialist Conference (PVSC), New Orleans, LA, USA, 14-19 June 2015; IEEE: Piscataway, NJ, USA, 2015. 
45. Zhang, C.; Zhang, Y.; Guo, H.; Jiang, Q.; Dong, P.; Zhang, C. Efficient planar hybrid n-Si/PEDOT: PSS solar cells with power conversion efficiency up to 13. 31\% achieved by controlling the SiOx Interlayer. Energies 2018, 11, 1397.

46. Deal, B.E.; Grove, A. General relationship for the thermal oxidation of silicon. J. Appl. Phys. 1965, 36, 3770-3778. [CrossRef]

47. Kim, W.-B.; Asuha, M.T.; Kobayashi, H. Ultrathin $\mathrm{SiO}_{2}$ layer on atomically flat Si (111) surfaces with excellent electrical characteristics formed by nitric acid oxidation method. Appl. Phys. Lett. 2008, 93, 072101. [CrossRef]

48. Moldovan, A.; Feldmann, F.; Krugel, G.; Zimmer, M.; Rentsch, J.; Hermle, M.; Roth-Fölsch, A.; Kaufmann, K.; Hagendorf, C. Simple cleaning and conditioning of silicon surfaces with UV/ozone sources. Energy Procedia 2014, 55, 834-844. [CrossRef]

49. He, L.; Jiang, C.; Wang, H.; Lai, D.; Rusli. High efficiency planar Si/organic heterojunction hybrid solar cells. Appl. Phys. Lett. 2012, 100, 073503. [CrossRef]

50. Chhabra, B.; Bowden, S.; Opila, R.L.; Honsberg, C.B. High effective minority carrier lifetime on silicon substrates using quinhydrone-methanol passivation. Appl. Phys. Lett. 2010, 96, 063502. [CrossRef]

51. Avasthi, S.; Qi, Y.; Vertelov, G.K.; Schwartz, J.; Kahn, A.; Sturm, J.C. Silicon surface passivation by an organic overlayer of 9, 10-phenanthrenequinone. Appl. Phys. Lett. 2010, 96, 222109. [CrossRef]

52. Miramond, C.; Vuillaume, D. 1-octadecene monolayers on Si (111) hydrogen-terminated surfaces: Effect of substrate doping. J. Appl. Phys. 2004, 96, 1529-1536. [CrossRef]

53. Liu, C.; Zhang, P.; Zhai, X.; Tian, F.; Li, W.; Yang, J.; Liu, Y.; Wang, H.; Wang, W.; Liu, W. Nano-carrier for gene delivery and bioimaging based on carbon dots with PEI-passivation enhanced fluorescence. Biomaterials 2012, 33, 3604-3613. [CrossRef]

54. Liu, D.; Zhang, Y.; Fang, X.; Zhang, F.; Song, T.; Sun, B. An 11\%-power-conversion-efficiency organic-inorganic hybrid solar cell achieved by facile organic passivation. IEEE Electron Device Lett. 2013, 34, 345-347. [CrossRef]

55. Alemu, D.; Wei, H.-Y.; Ho, K.-C.; Chu, C.-W. Highly conductive PEDOT: PSS electrode by simple film treatment with methanol for ITO-free polymer solar cells. Energy Environ. Sci. 2012, 5, 9662-9671. [CrossRef]

56. Song, I.; Park, N.Y.; Jeong, G.S.; Kang, J.H.; Seo, J.H.; Choi, J.-Y. Conductive channel formation for enhanced electrical conductivity of PEDOT: PSS with high work-function. Appl. Surf. Sci. 2020, 529, 147176. [CrossRef]

57. Li, J.; Liu, J.-C.; Gao, C.-J. On the mechanism of conductivity enhancement in PEDOT/PSS film doped with multi-walled carbon nanotubes. J. Polym. Res. 2010, 17, 713-718. [CrossRef]

58. Hosseini, E.; Kollath, V.O.; Karan, K. The key mechanism of conductivity in PEDOT: PSS thin films exposed by anomalous conduction behaviour upon solvent-doping and sulfuric acid post-treatment. J. Mater. Chem. C 2020, 8, 3982-3990. [CrossRef]

59. Jeong, S.-H.; Woo, S.-H.; Han, T.-H.; Park, M.-H.; Cho, H.; Kim, Y.-H.; Cho, H.; Kim, H.; Yoo, S.; Lee, T.-W. Universal high work function flexible anode for simplified ITO-free organic and perovskite light-emitting diodes with ultra-high efficiency. NPG Asia Mater. 2017, 9, e411. [CrossRef]

60. Sarkar, B.; Jaiswal, M.; Satapathy, D.K. Swelling kinetics and electrical charge transport in PEDOT: PSS thin films exposed to water vapor. J. Phys. Condens. Matter 2018, 30, 225101. [CrossRef]

61. Cruz-Cruz, I.; Reyes-Reyes, M.; Aguilar-Frutis, M.A.; Rodriguez, A.G.; López-Sandoval, R. Study of the effect of DMSO concentration on the thickness of the PSS insulating barrier in PEDOT: PSS thin films. Synth. Met. 2010, 160, 1501-1506. [CrossRef]

62. Mahato, S.; Puigdollers, J.; Voz, C.; Mukhopadhyay, M.; Mukherjee, M.; Hazra, S. Near 5\% DMSO is the best: A structural investigation of PEDOT: PSS thin films with strong emphasis on surface and interface for hybrid solar cell. Appl. Surf. Sci. 2020, 499, 143967. [CrossRef]

63. Thomas, J.P.; Zhao, L.; McGillivray, D.; Leung, K.T. High-efficiency hybrid solar cells by nanostructural modification in PEDOT: PSS with co-solvent addition. J. Mater. Chem. A 2014, 2, 2383-2389. [CrossRef]

64. Lin, Y.-J.; Lee, J.-Y.; Chen, S.-M. Changing electrical properties of PEDOT: PSS by incorporating with dimethyl sulfoxide. Chem. Phys. Lett. 2016, 664, 213-218. [CrossRef]

65. Hu, Z.; Zhang, J.; Zhu, Y. Effects of solvent-treated PEDOT: PSS on organic photovoltaic devices. Renew. Energy 2014, 62, 100-105. [CrossRef]

66. Choi, J.-Y. Understanding of Molecular Contribution of Quinhydrone/Methanol Organic Passivation for Improved Minority Carrier Lifetime on Nanostructured Silicon Surface. Appl. Sci. 2019, 9, 3645. [CrossRef]

67. Zou, Z.; Liu, W.; Wang, D.; Liu, Z.; Jiang, E.; Wu, S.; Zhu, J.; Guo, W.; Sheng, J.; Ye, J. Electron-selective quinhydrone passivated back contact for high-efficiency silicon/organic heterojunction solar cells. Sol. Energy Mater. Sol. Cells 2018, 185, $218-225$. [CrossRef]

68. McIntosh, K.R.; Black, L.E. On effective surface recombination parameters. J. Appl. Phys. 2014, 116, 014503. [CrossRef]

69. Kato, H.S.; Kawai, M.; Akagi, K.; Tsuneyuki, S. Interaction of condensed water molecules with hydroxyl and hydrogen groups on Si $(00$ 1). Surf. Sci. 2005, 587, 34-40. [CrossRef]

70. Zheng, W.; Sun, C.; Bai, B. Molecular dynamics study on the effect of surface hydroxyl groups on three-phase wettability in oil-water-graphite systems. Polymers 2017, 9, 370. [CrossRef] [PubMed]

71. Li, S.; Wen, X.; Zhou, J.; Zheng, N.; Liu, L.; Xie, Z. Construction of Interface Dipoles by Surface Doping and Their Role in the Open Circuit Voltage in Polymer Solar Cells. Org. Mater. 2020, 2, 71-77. [CrossRef] 